\title{
A Theoretical Inquiry into the Ethics of Mathematics Teaching
}

\section{Paul Ernest}

University of Exeter, United Kingdom

Corresponding author: P.Ernest@exeter.ac.uk

\section{ARTICLE HISTORY}

Received : 3 February 2019

Revised : 20 June 2019

Accepted : 10 September 2019

\section{KEYWORDS}

Ethics of Mathematics; Teaching;

A Theoretical Inquiry;

\begin{abstract}
This paper explores the ethics of the mathematics teacher, starting from the ethical obligations that all human being and professionals share towards those in their care. Most notably this involves a duty of care for students, since teachers can be the most influential persons after their parents. The ethics of mathematics teaching is analysed as concerning the aims of school mathematics, the selection of pedagogy, and the selection of content. The equal treatment of all students is also a central principle, although there are ethical dilemmas posed by the spread of achievement levels in mathematics. The ethical content of school mathematics itself is also considered, although this is a controversial issue. The paper notes that the modern tendency is for teachers to be viewed almost as technicians delivering the centrally decided mathematics curriculum. This paper argues that teachers have ethical agency which can and should still be exercised while meeting professional and institutional obligations.
\end{abstract}

This is an open access article under the CC-BY-SA license.

\section{INTRODUCTION}

In investigating the mathematics teacher and ethics many of my conclusions apply to all teachers and lecturers. For sure in looking at the ethical implications of the aims of teaching mathematics I draw some conclusions specific to the mathematics teacher. Nevertheless I am sure that any teacher or lecturer can soon make the findings relevant and applicable to their own subjects.

How does ethics concern the mathematics teacher? What is ethical mathematics teaching? It seems clear that mathematics teaching is an ethical undertaking, for it is intended to educate students, to enhance their knowledge, skills and thus their life chances. Ethics is about the good, about behaving in a way that benefits others and enables their flourishing. Thus ethics enters into all aspects of human life and professions, and that includes the teaching of mathematics.

In my analysis, the ethics of the mathematics teacher can be seen in terms of two sets of nested responsibilities, first, those of all humans, and second, those of all professionals. The ethics of mathematics teachers is a special case of professional responsibility, and is treated third.

First, all human beings have responsibilities towards other humans and to society, as well as to the environment and the living world. Humans are social creatures who not only are and have been fully dependent on others but who are largely formed through their relationships with others. No one can become an adult, let alone a healthy and balanced one, without the care and support of others. We therefore owe everything to others, including being honest, respectful, caring, supportive and attentive to their needs (Levinas,1972). This debt can be expressed in a number of ways. All religions promote the golden rule: Treat others as you wish to be treated yourself' and the silver rule: 'First, do no harm', which is the Hippocratic Oath that medics swear. As well as having religious foundations, these rules have humanistic grounds, stemming from the social nature of humankind described above. They represent some of our universally shared human responsibilities. ${ }^{1}$

In our responsibility to others there is no special class of persons that are included or excluded, or that deserve special treatment unless they are especially needy and require particular support, such as babies and children, the aged, the infirm and the handicapped. Thus the primary ethical responsibility to others, deriving from our humanity, commits us to equal treatment of and for all, and thus to a socially just approach to others irrespective of social class, nationality, race, creed, religion, sex, sexual orientation, disability, and soon ${ }^{2}$.

Second, all professionals have responsibilities towards the institutions of which they are a part, and towards the roles that they undertake. Any professional, including the mathematics teacher, has ethical responsibilities to (1) support colleagues, (2) participate in supporting and enhancing the institution and its goals, (3) carry out their own professional duties to the best of their abilities, (4) support and enhance their own profession and its standing in society, presuming this is warranted, as it normally is. Why do professionals have these responsibilities? To become a professional is to voluntarily accept a professional code of conduct and responsibilities in exchange for what is mostly pleasant and enhancing work, with protected job security,

\footnotetext{
1 In basing my account on ethical imperatives I am following deontological ethics, one of the three main schools in philosophical ethics, which puts an absolute moral imperative at the summit of any hierarchy of ethical obligations.
} 
elevated social status, and good financial rewards. Most vocational occupations are also personally enhancing for professionals because they work with a degree of autonomy in an environment of trust, and generally find fulfilment through deploying their capabilities, skills, and creativity in practice. In addition, professionals can take satisfaction from knowing that they are contributing to the overall good of society.

The responsibility to support colleagues can involve being a member of the appropriate professional associations or unions, and participating in the training of younger colleagues. Supporting a professional institution and its goals may involve taking on senior administrative and managerial positions to help to sustain and enhance the institutions. Persons may participate and take on such positions for a variety of reasons and motives, including political motivations or personal ambitions, but providing they are working for the benefit of the institutions from some ethical perspective such involvement is ethically defensible, or in a word, good.

However, it should be acknowledged that there are ethical risks in taking on roles with power and privileges. First, there is the risk of becoming aligned with the institution at the cost of the interests of those represented and managed, if these diverge. As a leader in an institution one has the responsibility to represent the interests and well-being of one's team and ones clients, and to resist policies and practices antithetical to these interests, even if they come from 'on high'. Second, positions of responsibility and power come with privileges and rewards. These are benefits associated with the position, enablers of the leadership role, and not personal entitlements of the role-holder. For leaders, there is the ever-present danger of succumbing to inflated notions of self importance and entitlement. As the well known dictum says 'power tends to corrupt' (and absolute power corrupts absolutely). (Dalberg 1887). Thus promoted roles of responsibility within an institution bring with them their own ethical challenges.

Third, a mathematics teacher has specific additional responsibilities because of the particular nature of their job of teaching mathematics to students. These are: (1) To treat students with care and respect, (2) To teach mathematics in an effective way that benefits the students, (3) To be engaged with the profession and keep up to date with research and developments, and to maintain their own interest and enthusiasm. Why does a mathematics teacher have these responsibilities? They follow from the responsibilities all professionals accept voluntarily in becoming a professional. That is, to carry out their professional duties to the best of their abilities, including respecting clients, practicing their profession well, and enhancing their profession overall.

Based on the perspective of the mathematics teacher, this last (third) set of responsibilities is the one that relates to the specifics of the job, that is teaching mathematics to students in a school or college. However before expanding on the details of these ethical demands, a caveat is needed concerning the high professional standards laid out here. It is a fact of life that these simple idealistic sets of responsibilities are frequently compromised, and that this does not make the professionals themselves unethical. Such compromises may occur, first, because there are competing and conflicting demands within the context of professional practice. Second, normal human beings cannot operate optimally at all times. Such shortfalls are usually because of problems and conflicting demands within the personal life of the professional.

Within the professional situation, the school or college, in the cases I am considering, there can be a number of types of competing, conflicting and even contradictory demands. These can stem from many things including inconsistent or problematic management directives; disrespectful uses of power; complaints and challenges to professionals from insiders and outsiders (including inspectors, students and parents); inter-staff conflicts; staff shortages; unexpected disruptions including those cause by unruly students; resource shortages; overcrowding; environmental degradation; new curriculum and assessment demands and more generally changes in the professional situation that conflict with established practices. All of these can be accommodated professionally and ethically in a learning and growing institution that seeks to identify and overcome problems and obstacles. However, this requires the commitment and involvement of the leadership and managerial team in maintaining a values driven ethos for the whole institution.

Secondly, personal life challenges may compromise professional functioning. Anything from illness, stress and family issues to financial problems and being a victim of crime may interfere with a professional's ability to operate optimally. Provided that the individual has the active long term goal of reducing and overcoming these obstacles to effective professional practice, including seeking help where necessary, these are not significant ethical lapses. Optimal professional functioning should be a perpetual goal even if it is not always achieved or immediately achievable.

\section{LITERATURE REVIEW}

\subsection{Ethical Mathematics Teaching}

What constitutes ethical mathematics teaching is the most specific and unique aspect of the discussion of ethics and education from the point of view of the mathematics teacher. I distinguish three aspects.

First, there is the duty of care for one's students, shared with all teachers.

Second, there is the teaching mathematics effectively so as to benefit students. This is by far the most complex of these notions and responsibilities to unpick. ${ }^{2}$

Third, there is the engagement with the profession of teaching so as to keep up to date and maintain one's enthusiasm. Engagement with the profession should also involve 'giving back': participating in professional bodies, reflecting on the nature of the mathematics curriculum and its assessment, maintaining up-to-date expertise and knowledge of relevant research, and supporting and contributing to the initial and in-service training of colleagues.

There is nothing intrinsically mass-orientated, that is requiring a medium to large-sized class, in mathematics teaching or indeed teaching any subject. Teaching may be conducted by a teacher with varying any numbers of students from a single one, to virtually any number, given suitable

\footnotetext{
2 The adjective 'effective' is troublesome because it hides a more complex relation. If we say an action is effective, we mean that the action is judged to be effective by a group of persons in attaining a particular set of objectives. Thus there are hidden dimensions concerning: Who makes the judgement? On what evidential basis? With respect to which objectives?
} 
accommodation, planning and resources. ${ }^{3}$ Typically teaching to groups of size 12, 30 or 60 is done in order to economise on teacher time and resources. There are of course benefits to whole class teaching. Students can and should learn from peer interaction, and seeing other group members' processes, strategies and errors displayed and discussed in class is a valuable teaching and learning technique that is difficult if not impossible to use in one-to-one tuition. On the other hand, there are benefits to individual or small group teaching. The teacher can devote a significant amount of time and attention to individual students to evaluate their responses to presentations of mathematics and tasks, to assess their progress, to attend to their working methods and come to understand their personal problem solving strategies, to diagnose their strengths, weaknesses and needs, and to tailor an individualised learning/teaching experience to meet these needs. However, in suitably organised classes of 3 to 40 students a flexible teacher should be able to balance the benefits of whole group activities with individual attention, although sometimes with difficulty.

Attending to their individual needs is part of one's duty of care for students. Treating them respectfully, benignly, equally and consistently is another part. This includes not singling students out for approbation or ridicule for lapses or errors in their mathematical reasoning, no matter how elementary, apparently stupid or recurrent they are. There is strong if anecdotal evidence that being singled out and publically criticised or humiliated for mathematical errors or lapses in class can lead to loss of mathematical confidence and even mathephobia or fear and hatred of school mathematics among sensitive students. One small negative interaction can have lasting deleterious effects. Likewise one small positive interaction valuing a student's insight or mathematical work can have lasting beneficial effects, impacting of the student's attitudes to mathematical work and to mathematics in general. Neither of these outcomes can be predicted as they depend on students' sensitivities, interpretations and emotional responses to varying stimuli in the moment. But a teacher should always be sensitive to these possibilities.

The question of how one should attend to students' individual needs in a whole class situation leads to an important ethical dilemma. All classes contain students with a spread of achievement levels in mathematics. Should the teacher target the average achievement level in the class, choose teaching targets and learning activities accessible to all of the students, or focus especially on the highest attainers? One solution is to offer a range of tasks of different cognitive demands so that students work at the level that suits them best. ${ }^{4}$ Overall, accommodating the various achievement levels

\footnotetext{
3 Team teaching with multiple teachers is another form of organization, albeit less common. More common is working with helpers or support teachers in a classroom. Neither of these brings in any completely new ethical responsibilities beyond committed membership and working within a team of teachers.

4 Setting tasks so that a student works at the level that suits them best is to work within the student's Zone of Proximal Development ZPD (Vygotsky 1978). That is setting tasks that exceed the learner's cognitive capacity unaided, but is within their reach when aided by another person's guidance, be it teacher, parent or peer. One example of such tasks for a range of students are Rich Mathematical Activities that allow entry across a range of difficulty or ZPD levels (Griffin, 2009). However there is as yet little published research on the proven efficacy of this approach.
}

of a class of students and setting appropriately demanding work is a significant ethical responsibility of the mathematics teacher.

However, a mathematics teacher should never lose sight of the fact that a student's pattern of achievement is not a reliable reflection of their competence or ability. Various factors can depress a student's achievement scores below the level of which they may be capable. So it is a vital ethical responsibility not to form stereotyped expectations of student abilities. The underestimation of the educational potential of female students in mathematics was for many years a factor that depressed their average achievement scores.

\subsection{The Responsibilities Of Teaching Mathematics}

The responsibility to teach mathematics in an effective way that benefits the students, is a very complex and multifarious one. Value judgements are involved in (1) deciding the effectiveness of a teaching approach in a particular situation (2) deciding what is of benefit to the students. To determine the effectiveness of a pedagogical approach one needs some means of rigorously assessing its effects in terms of educational gains. Furthermore, such gains can only be established against a set of educational goals and objectives. Thus, to establish what benefits students one needs to have determined a background set of goals for their mathematical education. Ideally a set of aims and goals, properly determined, represents what is beneficial for the students and good for society, although it is conceivable that these two interests might clash. But there is no one set of goals good for all students, nor can a single set of goals be wholly beneficial for society. For it depends on values, priorities, as well as underlying ideologies.

\subsection{Aims, Curriculum And Ethics}

During the development of the British National curriculum in the late 1980s and 1990s five interest groups were identified as contesting over the aims and goals of the mathematics curriculum (Ernest 1991).

Each of these five groups thought that their own aims were best for the country, for developing the good society, according to their own lights. However, it can be shown that such aims are not always best for all the students in school. To demonstrate this it is necessary to evaluate each of the aims from an ethical perspective.

The first group, called the Industrial Trainers, have the main goals for the bulk of the populace of teaching basic mathematical skills and numeracy as well as a social training in obedience. This is to prepare a compliant workforce with the basic skills necessary for routine jobs. This group does not want education politicised in order to prepare a demanding and non compliant workforce. These aims are not intended for the future elite who are educated in private schools and to which the National Curriculum does not apply. What is unethical about these aims is that they support an elitist stratified society that does not provide the best life chances for the masses. The good life of these workers, and the development of their knowledge, skills and interests beyond drudgery and material consumption is discounted and not supported. The goods of life are reserved for a minority elite at the cost of the masses. 
Table I: Five interest groups and their aims for mathematics teaching

\begin{tabular}{|c|c|}
\hline Interest Group & Social Location \\
\hline 1. Industrial Trainers & $\begin{array}{l}\text { Radical 'New Right' conservative } \\
\text { politicians and petty bourgeois }\end{array}$ \\
\hline $\begin{array}{l}\text { 2. Technological } \\
\text { Pragmatists }\end{array}$ & $\begin{array}{l}\text { Meritocratic industry-centred } \\
\text { industrialists, managers (later to } \\
\text { include New Labour), etc. }\end{array}$ \\
\hline $\begin{array}{l}\text { 3. Old Humanist } \\
\text { Mathematicians }\end{array}$ & $\begin{array}{l}\text { Conservative mathematicians } \\
\text { preserving purity of mathematics } \\
\text { and rigour of proof }\end{array}$ \\
\hline $\begin{array}{l}\text { 4. Progressive } \\
\text { Educators }\end{array}$ & $\begin{array}{l}\text { Professionals, liberal educators, } \\
\text { welfare state supporters }\end{array}$ \\
\hline 5. Public Educators & $\begin{array}{l}\text { Democratic socialists and radical } \\
\text { reformers concerned with social } \\
\text { justice and inequality }\end{array}$ \\
\hline
\end{tabular}

The second group, the Technological Pragmatists, have the aims of teaching the mass populace both basic skills and the higher knowledge and skills needed to solve practical problems with mathematics and information technology. These goals are industry and work centred, but they serve a meritocratic vision of society in which through education some persons from lower socio-economic backgrounds can become professionals thus having more rewarding careers both in terms of satisfaction and pay. The vision of society served is still an elitist and stratified one, but embodies permeable class barriers that allows for individuals to find their own level according to their educational achievements. This is a more egalitarian and ethical vision, but is superficial in considering only educational outputs (achievements) and not the inputs 5 , namely the educational potentials of all students and what needs to be provided in order to realize their talents.

The third group the Old Humanist mathematicians have aims that are pure mathematics centred, trying to maximise student understanding and capability in advanced mathematics, including an appreciation of mathematics. This group have an elevated view of the intrinsic value of mathematics and believe it should be emphasised for all students, in so far as they are capable, to preserve the rigour of proof and purity of mathematics and develop more professional mathematicians. Mathematics is a good in itself, as well as being important and useful in society. But to distort the education of the masses to favour the less than $0.1 \%$ of the population who will become mathematicians, and the less than $1 \%$ who will professionally apply mathematics is ethically unsupportable.

Each of these three groups strongly subscribes to a belief in inherited mathematical ability and is committed to tests in mathematics to separate students out by ability. This leads to the view that very differentiated goals and aims are appropriate across the range of mathematical 'abilities' (as manifested in mathematical achievement levels).

The Progressive Educators aim for students to learn to be creative, to express themselves and to gain confidence through learning mathematics. The aim to encourage the development and flowering of the whole person is ethically commendable. But overemphasised it is unrealistic because learning mathematics is to a large extent reproductive, mastering the

\footnotetext{
5 This is what Bourdieu terms 'cultural capital', the partly hidden cultural knowledge, material resources and enhanced attitudes that children of the middle and upper classes carry with them into schooling to their own advantage.
}

Mathematical Aims

Acquiring basic mathematical skills and numeracy, and social training in obedience (authoritarian, basic skills centred aims) Learning basic skills and learning to solve practical problems with mathematics and information technology (industry and work centred aims)

Understanding and capability in advanced mathematics, with some overall appreciation of mathematics (pure mathematics centred aims)

Gaining confidence, creativity and self expression through mathematics (child-centred progressivist aims)

Empowerment of learners as critical and mathematically literate citizens in society (empowerment and social justice aims) knowledge of past generations through the practice and reinforcement of skills, as well as developing some competence in problem solving. Creativity is possible in school mathematics but is a small component compared to the required mastery of knowledge and skills. In addition, all mathematics teachers must address school examinations and assessments, as these are major passports to enhanced life chances.Thus progressivism suffers from being individual-centred at the cost of not being socially aware and responsive. This is putting individual goods ahead of social goods, and doing so unrealistically. It is also very difficult to implement in practice and there is little research evidence that progressive teaching programmes result in higher achievement or more positive attitudes in mathematics.

For Public Educators, the main goal is the empowerment of learners as critical and mathematically literate citizens in society. Again these are very worthwhile aims which are good both for individuals and for society, since the promotion of democracy and social justice are ethical goods. However, there is a danger that the needs of individuals become secondary to social goals, and for education to become too politicised. The politicisation of education creates social conflict and opens the door to subsequent swings in the political orientation towards ideological or reactionary doctrines. In addition to the public educator goals, students need to develop their own individual interests and talents, as well as preparing for examinations, for the reasons discussed above. In developed countries there is little or no evidence of the success of Public Educator programmes in school mathematics, especially since none of this type have been tested on a large scale. Where they have been successful is in second chance adult education programmes (Frankenstein 1989).

However, it must be acknowledged that only the Public Educators offer a set of aims for school mathematics with an explicit ethical dimension. Using mathematics as a vehicle for raising ethical issues in the classroom, including social justice for humans, care for animal welfare and care for the earth and the environment can only be good thing. Using real world examples from such areas as a source of problems and modelling applications not only helps to develop student skills, concepts and strategies, but also motivates problem solving. Including ethical issues in the mathematics curriculum in this way provides the mathematics teacher with an additional asset. Thus the benefits go beyond merely adding ethics to the curriculum, they both enliven study and help to develop students as balanced and rounded human beings.

This justification raises the question of whether an ethical mathematics teacher should or must include ethical issues 
within the content of the mathematics curriculum. My opinion is that if this is done well it is a good thing, an asset to students and society. But to compel all mathematics teachers to include such content is problematic. For if politicising the mathematics curriculum runs contrary to the philosophy or beliefs of the teacher then until ethical content is mandated by law compulsion would not seem to be right. Furthermore, an unwilling teacher may not make the best case for ethics in mathematics and its applications. However, times may change. For example, in Australia a number of Universities including La Trobe have made sustainability education and global citizenship, which share some common ground with the Public Educators aims, a necessary component for undergraduate students in all subjects (Good Universities Guide, 2018).

What this evaluation of the aims of these five groups nevertheless shows is that even though some of the aims are more ethically defensible than other, no single one of them can claim to be ethically the best and wholly good for all. Historically, the five groups proposing these aims have been in conflict, so each group has fought to increase the emphasis on their own particular aims in the overall outcome. Thus since no one of these aims is the best on its own, a balance between them, a compromise, is desirable, in which the weakness of some are balanced by the strengths of others.

Over time it was not the optimal ethical compromise between the group aims that was adopted, but the relative power and dominance of the groups that determined the outcome. Of course the outcome has not been static through the years. At the beginning the Progressive Educators and their aims played a significant role in the development of the National Curriculum in mathematics, since this was the dominant ideology of the mathematics educationists involved in its formulation. They succeeded in including progressive activities including investigational work, extended projects and problem solving in the mathematical National Curriculum and its assessment. However over the course of the 1990s the influence and the inclusion of Progressive Educator aims has been all but eradicated from the National Curriculum. Against this declining influence, in the late 1990s the National Numeracy Strategy emerged which included more emphasis on mental mathematics and individual student reasoning which supports the Progressive Educator aims. But the net overall effect is that the emphases on progressive elements such as problem solving strategies and investigational work have only survived insofar as they could be represented as applications of mathematics in such curriculum elements as Using and Applying Mathematics, thus more directly serving the aims of the Technological Pragmatists.

The aims of the Public Educator group were never reflected in the mathematics curriculum at any stage, and the aims of the first three groups have come to dominate. These are basic instrumental numeracy for the lowest attainers, practical mathematics and teaching to the tests for the majority, and higher mathematics for the highest attainers destined for university or scientific professions. These are not optimal ethical outcomes. More emphasis on Progressive Educator aims would better round out the personal development of students, enhancing their flourishing. More emphasis on the Public Educator aims would empower students as critical citizens better able to contribute to and sustain a democratic open society, and concerned with social justice and environmental problems. This is evidently an ethical good, not currently addressed in school mathematics.

\subsection{Pedagogy and Ethics}

Teaching is fundamentally about the interaction of teachers and students. Underlying this is the one to one relationship between a teacher and a student. Normal interpersonal ethics apply, as discussed above, plus there are additional considerations because the teacher is responsible (and in loco parentis) for the student if a child, that is, under 18 years of age. In addition to individual relations there is also the relationship between the teacher and the whole class. This a complex relationship because the teacher must apportion their time between addressing or managing the whole class, attending to subsets of the class, and giving attention to individual students, and doing all of these serially or even simultaneously. These complex relationships entail complex ethical compromises. The modes of contact with individuals will be limited by the needs and demands of other individuals or subsets of the class. Some students may explicitly or implicitly (through their behaviour) demand attention which can only be given at cost to other individuals. Sometimes teachers will need to withhold attention to individual students in order to manage the whole class. In the short term this might seem like neglect or unethical behaviour but in the long may result in better learning conditions for all, which is an ethically defensible and indeed desirable outcome.

All of these interpersonal ethical issues make up the background against which the teacher chooses and applies a pedagogy, that is a mix of teaching methods, styles and techniques to enable student mathematics learning. Every teacher uses a mix of teaching styles such as teacher exposition; teacher-student discussion including question and answer and discussion with the whole class and with individual students; the setting of exercises, for the practice and reinforcement of skills, as well for the solution of routine and non-routine problems. The teaching styles employed can also include open-ended problem solving, also known as investigational work, as well as practical work, using either material teaching resources, or applied practical work or modelling. Less common is group work such as group problem solving including group discussion between students. This list is only illustrative for there are many other teaching modes including, for example, the use of homework to develop concepts and to extend the practice and reinforcement of skills and problems. Another pedagogy involves computer mediated teaching and learning of mathematics.

It is very difficult to make an ethical assessment of pedagogy because this necessitates taking into account teacher intensions and plans (short, medium and long term), the demands of the social milieu (including using prescribed and proscribed teaching methods), the views of and pressures exerted by students, parents, other teachers, school administration, inspectors, and so on. It also involves assessing the efficacy of the pedagogies, as employed in practice, in terms of a range of different outcomes including achievement gains, understanding, and affective outcomes. Rarely discussed is another outcome, the student's eagerness to pursue further studies in mathematics at the end of a course or school year. Any evaluation of the effectiveness of teaching, let alone its ethics, presupposes a set of values and an ideology incorporating the overall background curriculum, assessment and pedagogical assumptions of the teachers, department, school, district and national education frameworks. 
What can be said is that no easy good-bad ethical judgements can be applied to pedagogical styles. Open progressive pedagogies which claim to develop autonomy and creativity cannot claim the moral high ground over traditional pedagogies aiming to inculcate skills and mastery in mathematics. Practical applications of such pedagogies can only claim virtue to the extent that they are successful in achieving their aims, as well as resulting in gains in achievement and the mathematical certification that students need to better their life chances. In one well known study the most effective pedagogy was not the progressive or traditional style. The most effective was a teaching approach that concentrated on improving student understanding in terms of well integrated and linked mathematical concepts, and which focused on individual thinking and mathematical working methods (Askew et al 1997). This challenges the widely held belief that progressive teaching methods are superior to others approaches both in terms of efficacy and ethics.

I should note that there is more to pedagogy than pedagogical style. Teaching is based on content and the teacher has specialist pedagogical content knowledge in mathematics, as in every subject. This includes knowledge of examples, applications, experiments, activities and tasks in mathematics, as well as ways of exemplifying, illustrating, explaining mathematical concepts and strategies. Some of this knowledge is represented in student text books and teacher guide books, but often these texts follow a single explanatory or study track. An experienced teacher will know of alternatives that can be accessed to offer different explanations when needed, or can be used to exploit current items of interest to students, such as sport or other popular media events. It is at this point that a teacher can utilise examples or activities of ethical relevance, such as tasks concerning environmental degradation, recycling, wildlife problems and extinctions caused by overdevelopment, trade and poverty in developing countries, international differentials in longevity, health and child survival rates, and many similar themes. All such topic areas are rich in quantitative data which can be analysed, represented and displayed offering practice in numerical and statistical skills. An impartial analysis and display of the data is what is sufficient, as befits professional standards of teaching, for the learners can draw their own ethical conclusions from the facts. This is not to rule out class discussions of the ethical implications, with the teacher serving as an impartial chairperson. Such activities help students to develop their critical faculties and reasoning, reaching their own conclusions based on the data. ${ }^{6}$

There are many genuine ethical dilemmas that must be faced by mathematics teachers and lecturers. Should the emphasis in teaching be on the most able students, to enhance their mathematical talents and capabilities, thus benefitting these students, society and the institution of mathematics through the production of a skilled mathematical elite? Or should the emphasis in teaching be equally spread among learners but with special attention to the lowest attainers to raise their levels of skill and enhance their mathematical attitudes and self confidence. This is more egalitarian and means that all students are helped to achieve mathematically, being thus of benefit to the student, to all in

\footnotetext{
6 Any attempt to propagandise or to sway the students politically is unethical. It is a betrayal of the trust in and duty of the teacher to remain neutral and to encourage students to develop as citizens in their own, self-determined directions.
}

education and for the benefit of society as a whole.

Different institutions have adopted different answers to these questions. Hersh (2018) reports that two well known universities in the USA have adopted these two different sets of priorities in their mathematics departments. One is known for its excellent prizewinning graduates, leaders in the field, but has a rather harsh and demanding study regime that only the truly excellent survive. The other is known for the support given to all students to ensure they graduate in mathematics, and is especially renowned for being supportive to female students. Given that students can choose which of these universities they apply for, and which regime they wish to follow, is it fair to say that one is more ethical than the other? Of course in mandatory schooling students do not have these same choices which means that the ethical question is different. It is good to demand excellence, but it is not good to belittle or ignore students who fall short of it, thus damaging their self esteem and possibly their subsequent life chances.

It is standard, and even a legal requirement in the UK for schools to meet a range of special educational needs across the curriculum and in mathematics. It can be argued that many if not most students have special needs at one time or another during their schooling. Warnock (1978) offers evidence at any one time, up to $20 \%$ of the school population may experience a 'special educational need'. If learners are having difficulty with one set of concepts or skills, or display exceptional talents and abilities in mathematics, or consistently lag behind their classmates in mathematics, or suffer from dyslexia or other identifiable conditions, they can be said to have special needs in mathematics. Once these needs are identified there is a legal responsibility on the school to provide additional learning support for these students. So the ethical dilemma of having to choose between giving one's attention to students with special needs or to the whole class should not arise, at least not in the medium to long term. ${ }^{7}$

Teaching is an ethical profession and what this discussion shows is that part of the responsibility of the teacher as professional is to make ethical judgements about what is best for every student in their care and for their classes as a whole. This is in addition to the other professional responsibilities discussed above. Perhaps a new definition of professional is needed. A professional is someone whose work inevitably involves ethical decision-making and responsibilities. No easy or formulaic solutions exist for the ethical decisions and dilemmas of education. The teacher as professional has to exercise good judgement in making sound ethical choices, and this is an inevitable and everyday part of the job. Although some of this is implicit in descriptions of teachers' roles and responsibilities, in general the ethical dimensions of teaching are understated. In Initial Teacher Education the ethical dimensions of teaching are often submerged beneath technical considerations of efficacy and instrumental concerns. Although these convey hidden values, including ethical considerations, they typically leave moral agency to those managing the schools and curriculum. Teachers are moral agents but they are led to believe that they are following social dictates and orders, rather than being reflective moral agents. One could say that in some cases they are being duped into enacting the ethical decisions and dictates of others, just

\footnotetext{
7 Unfortunately in times of financial hardship, such the current period of austerity in the UK, there is a reluctance to assess the needs of students because of the legal obligation to provide the extra support for special students once their needs have been determined.
} 
following orders' and thus not seeing or accepting their own ethical responsibilities. However, in an era where central control over the mathematics curriculum is increasing including mathematical content, pedagogy and assessment it is becoming more difficult for teachers to exercise independent judgement and 'do the right thing' by their own ethical lights.

\subsection{Teaching Ethics to Teachers}

What is the solution to the problem of the submerged ethical concerns in mathematics teaching? One obvious answer is to include explicit attention to the ethics of teaching and being a professional in the initial and in-service training of teachers. This need not be done explicitly throughout. Instead, it can involve reflection on and responses to situated ethical dilemmas in case studies, to video presentations, and through engagement in role play, for example. However some explicit discussion of the ethics of teaching and teachers as ethical agents is also called for, so that ethics is not wholly submerged and only addressed implicitly and incidentally. This will foreground the fact that teachers are indeed ethical agents and need to be both conscious of and conscientious about this.

Similar conclusions have been reached by West (2012) who argues that in the education of 'quants' (quantitative financial analysts) ethics is mostly absent, but needs to be included. These quants play a big role in financial markets and in the creation and promotion of derivatives and other financial instruments and products. Given the high stakes in these areas of finance, and given the gravity of national debt problems and the global financial market crash of 2008, for example, attention to the ethics of investments would seem to be essential. In Ernest (2018) I also make the case that ethics should be included in the education of mathematicians from school mathematics right up to university level, because of the great, but often underplayed, ethical role of mathematics in society. This fits with the call from West (2012) to include ethics in the education of quants, since quants are primarily applied mathematicians.

One of the few professions which does have explicit ethics and the teaching of ethics is medicine. UK trained doctors at all levels, and in all specialties, now receive formal ethics training at medical school. Medical ethics is based on a set of values that professionals can refer to in the case of any confusion or conflict. These values include the respect for autonomy, non-maleficence, beneficence, and justice (Wikipedia, n. d.). Other professions, like those of teaching and university lecturing can probably learn a great deal from what goes on in the ethics training at medical school. Unesco (n. d.), often a forerunner in the area of ethics, has been offering Ethics Teachers' Training Courses since 2007. These courses were initiated through concerns with Bioethics and Ethics of Science and Technology, but the course content is general and has pointers for teacher training in ethics more widely.

Of course I am not claiming that teaching and other professions cannot be ethical without the teaching of ethics. Human ethics is primarily learned through examples, from good upbringing, fair schooling and interpersonal interactions with others. However, my goal is to make teaching professionals more conscious about the ethics of their profession and to be aware if their own ethical agency. So in my view explicit attention to, and discussion of, the ethics of education is essential. It needs to be brought in right from the outset of teacher education. This is especially important for mathematics teachers because of the widespread idea that mathematics is ethics-free.

In recent years the subtext of official curriculum documents is that a teacher is just a skilled technician delivering the curriculum to classes of students, to be judged by targets achieved. Bringing ethics to the fore in a discussion of teaching reminds us that a teacher is a moral agent and that the relationship with students is paramount. It may sound idealistic but I believe the secret of outstanding teaching is care. Caring is a deep commitment to another person, the student in this case; caring about how they feel, about what interests them, about how best to support them in their present efforts, and their future ambitions. It involves talking to and listening to each student to uncover their passions, curricular or extra-curricular, and helping them to fulfil their dreams; academic, artistic, musical, sporting, or whatever. Of course these responsibilities are shared among all of a student's teachers. But I believe that when a student achieves success in any endeavour it energises their whole life including study and lets them focus their energies and grow into a contributing and, it is to be hoped, fulfilled member of society. Caring for students and helping them to achieve their best must be the greatest good a teacher can do.

\section{CONCLUSION}

Like all human beings and professionals, mathematics teachers share an obligation of care towards those in their charge. Exercising this responsibility at its best provides a source and model of inspiration for students, both in the present and for the future. Beyond this, ethical mathematics teaching requires an analysis and scrutiny of the aims of school mathematics and their implications, epistemologically, socially and ethically. Mathematics teachers share the obligation to consider the ethical consequences of different pedagogies, and selections of content and representations of content. The ethics of teaching must address the dilemmas posed by the spread of achievement levels in mathematics and to reconcile it with the obligation to provide an equal treatment of all students. There is a tendency for teachers to be viewed as technicians responsible for simply delivering the mathematics curriculum as decided by others. However, this paper argues that teachers should not and need not abnegate their ethical agency while meeting their professional and institutional commitments. By shouldering their ethical responsibilities, both the teaching and learning of mathematics become enhanced and more effective and rewarding for everybody concerned, teachers and students alike.

\section{REFERENCES}

Ali et al. (2010). Effect of using problem solving method in teaching mathematics on the achievement of mathematics students. Asian Social Science, 6 (2), 66-72.

Askew, M., Brown, M., Rhodes, V., Johnson, D. and Wiliam, D. (1997) Effective Teachers of Numeracy, Final Report, London: King's College, University of London.

Dalberg, J. E. M. (Lord Acton) (1887) Letter to Archbishop Mandell Creighton. Consulted 11 October 2018 at https:// history.hanover.edu/courses/excerpts/165acton. html 
Ernest, P. (1991). The Philosophy of Mathematics Education, London, The Falmer Press.

Ernest, P. (2018). The Ethics of Mathematics: Is mathematics harmful?. In P. Ernest (Ed.) The Philosophy of Mathematics Education Today, Switzerland: Springer international. pp. 187-216.

Frankenstein, M. (1989). Relearning Mathematics. London: Free Press.

Good Universities Guide, The (2018) What is global citizenship and what is its place in education? Retrieved 8 November 2018

https://www.gooduniversitiesguide.com.au/education-bl ogs/after-graduation/what-is-its-global-citizenship-andwhat-is-its-place-in-education

Griffin, P. (2009). What makes a rich task? Mathematical Teaching, No. 212, pp. 32-34.

Hersh, R. (2018) Ethics in Mathematics Teaching. Retrieved 1 September 2018 .

https: / / www.youtube.com/watch?v=5hOT8F9719Y\&start =4068\&end=5598 (Referring to R. Hersh \& V. John-Steiner. Loving and Hating Mathematics: Challenging the Myths of Mathematical Life. Princeton, New Jersey: Princeton University, 2011.)

Levinas, E. (1972) Humanisme de l'autre homme (Humanism and the Other, trans. N. Poller. Champaign, Illinois: University of Illinois Press, 2003).

Unesco (no date) Ethics Teachers' Training Courses. Retrieved 30 August 2018

http://www.unesco.org/new/en/social-and-human-scien ces/themes/bioethics/ethics-education-programme/activ ities/ethics-teacher-training/

Vygotsky, L. S. (1978) Mind in Society: The development of the higher psychological processes. Edited by M. Cole, V. John-Steiner, S. Scribner, E. Souberman., Cambridge, Massachusetts: Harvard University Press.

Warnock Report (1978) Report of the Committee of Enquiry into the Education of Handicapped Children and Young People. Chair, Mary Warnock. London: Her Majesty's Stationery Office.

West, J. (2012) Ethics and Quantitative Finance, Griffith Business School, Australia. Retrieved 30 August 2018 from

https: / / www120.secure.griffith.edu.au/research/file/7b0 1820e-e28a-490f-b698-5c6ec507c9a2/1/2012-04-ethicsand-quantitative-finance.pdf

Wikipedia (no date) Medical ethics. Retrieved 30 August 2018 from https://en.wikipedia.org/wiki/Medical_ethics 